\title{
Temporal form of shock is a determinant of magnitude of interference with escape-avoidance learning produced by exposure to inescapable shock
}

\author{
CHARLES R. CROWELL, J. VICTOR LUPO, \\ CHRISTOPHER L. CUNNINGHAM, and D. CHRIS ANDERSON \\ University of Notre Dame, Notre Dame, Indiana 46556
}

\begin{abstract}
The influence of differing temporal forms of inescapable shock on movement during shock and subsequent interference with escape-avoidance learning in the rat was examined using procedures patterned after those of Overmier and Seligman (1967). Results indicated that a series of inescapable shocks of an intermittent nature produced sustained movement during shock and no subsequent interference, whereas comparable exposure to a series of noninterrupted shocks resulted in immobility during shock and marked interference. Several interpretations of these findings were discussed and their implications for theoretical conceptions of the interference phenomenon were explored.
\end{abstract}

A series of 1967 studies indicated that dogs restrained in a Pavlovian harness and given a number of inescapable shocks through electrodes attached to the paws subsequently showed a marked inability to learn a two-way escape-avoidance response in the shuttlebox (Overmier \& Seligman, 1967; Seligman \& Maier, 1967). In contrast, when shock treatment in the Pavlovian harness included an escape contingency, no deficit in subsequent escapeavoidance learning was reported (Seligman \& Maier, 1967). These findings led Seligman and Maier (1967) to propose that uncontrollability of shock is the critical determinant of this interference-with-shuttle-learning phenomenon, which they termed "learned helplessness."

In the next decade, a number of published reports attempted to duplicate in rats the dramatic impairment reported for dogs following exposure to inescapable shock. In some instances, interference effects apparently were obtained (Glazer \& Weiss, 1976; Looney \& Cohen, 1972; Maier, Albin, \& Testa, 1973, Experiment 2; Maier \& Testa, 1975; Seligman, Rosellini, \& Kozak, 1975; Shurman \& Katzev, 1975). However, in each of these cases aspects of the shock treatment and/or test procedures used were significantly altered from those originally employed with dogs. In other studies, some closer but not identical methodologically to the original work, impairment effects were less dramatic, if present at all (Anisman \& Waller, 1972; Bracewell \& Black, 1974; Maier et al., 1973, Experiment 1; Mullin \& Mogenson, 1963; Weiss, Krieckhaus, \& Conte, 1968).

During this time, an unpublished series of studies from our laboratory used treatment and test procedures that closely resembled those employed by Overmier and Seligman (1967), but the results failed to reveal any indication of shuttle interference. An observation of potential significance that emerged from consideration of the failures concerned the temporal form of the treatment shock stimulus itself. Although always programmed to be inescapable, the shock used in our studies was a rapidly interrupted (pulsating) dc constant-current shock, whereas the stimulus used in dog studies was a noninterrupted (continuous) ac constant-voltage shock. Clearly,

The authors thank Constance Ormsby for her helpful assistance. Support was provided in part by NIMH Grant MH 14436. J.V.L. is now at the Department of Psy chology, Creighton University, Omaha, Nebraska; C.L.C. is at the Department of Medical Psychology, Oregon Health Sciences Center, Portland, Oregon. there are several differences between these shock stimuli, but one feature found to be important in other situations is the intermittency of shock (e.g., D'Amato \& Fazzaro, 1966). We overlooked the possible importance of this factor because pilot work indicated that an intermittent shock appeared more aversive than a continuous shock of the same duration and nominal intensity. Unsystematic observation showed that the pulsating stimulus produced vigorous movement and struggling during shock, while the continuous shock engendered relative immobility. Therefore, in the interest of obtaining a robust interference effect, we selected the seemingly more unpleasant intermittent shock as the treatment stimulus for our duplication efforts with rats.

In retrospect it is clear that we failed to consider the distinct possibility that the behavior produced during shock exposure may itself be a determinant of the subsequent effects of such stimulation, rather than serving merely as a reflection of functional shock intensity. Certain behaviors in the presence of shock at one time could transfer to the test situation and recur upon subsequent exposure to shock. Thus, the rat's response to test shock in the shuttlebox may be best predicted by behavior in the presence of treatment shocks. Interference effects would result if the transferred behavior was incompatible with the response required during testing. In the present context, this means that proactive consequences of exposure to pulsating or continuous shock may not be the same, even though both are programmed to be inescapable, because of different behaviors promoted by each. The first step toward verification of this possibility would involve a determination of the degree of shuttle impairment produced by comparable exposure to inescapable pulsating or continuous shock. At the same time, an assessment of the kind of behavior promoted by each treatment shock would be required.

This experiment served these purposes. Using procedures carefully patterned after early dog research, two groups of restrained rats were administered a series of either pulsating or continuous dc shocks. A dc shock was employed to avoid the possible complication of superimposing a pulsating rhythm upon a naturally varying stimulus. Two nonshocked control groups, one restrained and the other not, also were included. Gross body activity was monitored for each subject during treatment shocks to 
verify earlier observations regarding the disparate behavioral consequences of these stimuli. All groups were tested for interference effects using a conventional, two-way, discriminated, shuttle escape-avoidance learning paradigm.

\section{Subjects}

\section{METHOD}

Forty naive male Sprague-Dawley albino rats, $90-100$ days old, were used. They were housed in separate cages on an ad-lib food and water diet. All were handled and weighed daily, and were acclimated in the laboratory for 7-10 days prior to experimentation.

\section{Apparatus}

Shock treatment. A flat acrylic platform, supported on three wooden dowels over a plywood base, was used for restraining subjects (modified after Lykken \& Rose, 1959). The platform included separate relief areas for the subject's genitals, head, and limbs. One dowel was located between the forelimb holes, and one dowel behind each hindlimb hole. The platform was contained in a sound- and light-resistant ventilated refrigerator shell.

An Alton ultrasonic motion detector (Model 5) recorded movements during and between each treatment shock. The transmitting and receiving transducers of this device were mounted $9 \mathrm{~cm}$ apart on ringstands located $17 \mathrm{~cm}$ from the subject's right side. The front (receiving) transducer was perpendicular to the head and shoulder alignment of the subject. The sensitivity of the motion detector was adjusted to a setting of 1.0 , which readily recorded gross body movements (e.g., head turning) but not slight movements (e.g., respiration). The electronic circuitry for the device was located outside the subject enclosure.

The shock source was a constant-current tube-regulated dc device (Campbell \& Techtsoonian, 1958), set at $4.0 \mathrm{~mA}$, as measured with a 220-kohm resistance substituted for the subject. This shock could be interrupted 10 times/sec ("pulsating-shock" condition) with a Lehigh Valley pulse stream generator (Model 1670), which produced square-wave on-off times of $.05 \mathrm{sec}$. All treatment contingencies were controlled with solid state equipment and a laboratory computer housed in another room.

Testing. An $11.3 \times 59.7 \times 25.0 \mathrm{~cm}$ (inside) shuttlebox was used. The shuttlebox contained a grid floor $(.32-\mathrm{cm}$ diam stainless steel rods mounted $1.27 \mathrm{~cm}$ apart), stainless steel walls, a cylindrical hurdle $(5.1-\mathrm{cm}$ diam), and a $7.5-\mathrm{W}$ lamp that served as the CS, located $22 \mathrm{~cm}$ above the floor at each end of the chamber. The hurdle extended $6.3 \mathrm{~cm}$ above the floor and was mounted on ball bearings, thereby preventing the subject from perching on it. The grid floor was divided in half and microswitches were attached to each floor assembly. A full crossing from one compartment to the other was required in order to activate the switches and define a response. The test shock was the scrambled $40-\mathrm{V}$ ac output of a transformer wired in series with a 22-kohm resistor. The walls and hurdle were connected to the grid-shock circuit. The computer recorded response latencies and controlled all stimulus presentations.

\section{Procedure}

Shock treatment. The study was run in two identical replications, each with five subjects per group. The rats were ranked by weight for each replication, and animals in each block of four subjects were randomly assigned to one of four groups. Two groups were restrained and exposed to either a pulsating shock or a nonpulsating continuous shock. One nonshocked control group was simply restrained for a comparable period of time, while the other nonshocked control was unrestrained.

On each treatment day, each restrained subject was lightly anesthetized and strapped onto the acrylic platform by wrapping a 2 -in.-wide elastic bandage around the torso and by taping the forelimbs to the front dowel and the hindlimbs to the appropriate rear dowels. A polished copper electrode, lightly moistened with electrode paste, was firmly attached to the outstretched sole of each hind paw with adhesive tape. Treatment was given to each subject separately, and began approximately $10 \mathrm{~min}$ after etherization and $6 \mathrm{~min}$ after placement of the rat in the refrigerator shell.
Shock-treated subjects received 645 -sec shocks on each of 2 consecutive days at intervals averaging $60 \mathrm{sec}( \pm 15 \mathrm{sec})$. The restrained, nonshocked rats were treated identically to the shocked rats except that no shock was given. Unrestrained controls were anesthetized and placed in an operant chamber for a period comparable to that experienced by restrained subjects. Number of movements between and during shocks was recorded only for the shock-treated subjects, because the primary interest was in behavior during shock and because previous work showed that controls moved very little during treatment.

Testing. All subjects were given shuttle escape-avoidance training $24 \mathrm{~h}$ following the second shock-treatment day. After a 2-min adaptation period to the apparatus, 12 trials were given with a CS-US (light-shock) interval of $5 \mathrm{sec}$ and a variable intertrial interval of $60 \mathrm{sec}( \pm 30 \mathrm{sec})$. Trials terminated automatically after $60 \mathrm{sec}$ if the rat failed to respond. This procedure was repeated on each of the next 4 days for a total of 5 test days. Latency to respond after CS onset was recorded.

\section{RESULTS}

The replication factor was not a reliable source of variance, nor did it interact with other variables. The data therefore were collapsed across replications and are reported as a single experiment.

\section{Shock Treatment}

Movements during shock. The mean numbers of movements during shock presentations for each group, averaged over blocks of eight trials, are depicted in Figure 1. On Day 1, the continuous-shock (ConS) group made slightly fewer movements than the pulsating-shock (PS) group, and both showed some decline in movement over trial blocks. Although this pattern was unchanged in Group PS on Day 2, the ConS subjects exhibited a substantial decrease in mean movements between Days 1 and 2 .

An overall groups by days by trial blocks analysis of these data provided a significant Groups by Days interaction $[F(1,18)=5.6, p<.05]$, which prompted separate groups by trial blocks analyses for each day. The only significant effect from the analysis of the Day 1 data was due to trial blocks $[F(7,26)=2.1, p<.05]$. On Day 2, however, both the groups effect $[\mathrm{F}(1,18)=17.1, \mathrm{p}<.01]$ and the effect for trial blocks $[F(7,126)=3.4, p<.05]$ were significant.

Inasmuch as blocks of eight trials were used to summarize the data from Day 2, any progressive divergence

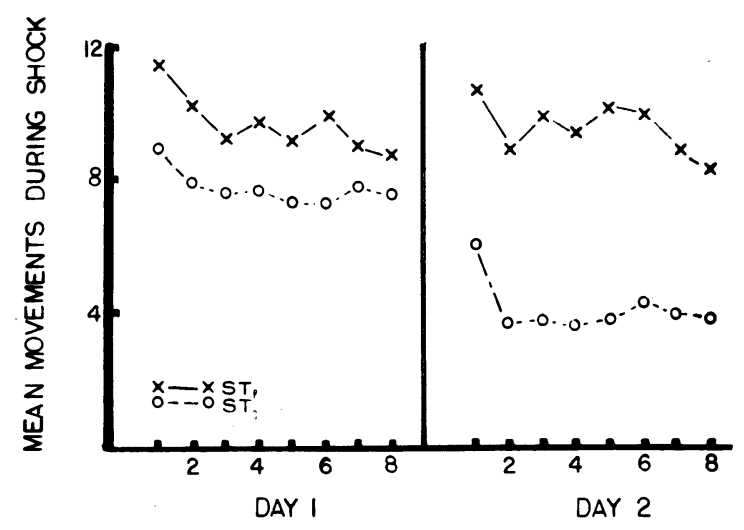

Figure 1. Mean movement/sec during shock for blocks of eight shock presentations on each of 2 treatment days. The continuous-shock group received noninterrupted inescapable shock treatments $\left(\mathrm{ST}_{\mathrm{c}}\right)$; the pulsating-shock group was exposed to intermittent inescapable shocks $\left(\mathbf{S T}_{\mathbf{p}}\right)$. 
of the two groups within the first block could have been obscured. Accordingly, a groups by trials analysis was applied to the data from the first eight trials of Day 2, producing a significant Groups by Trials interaction $(\mathrm{p}<.05)$; subsequent trial-by-trial analyses revealed that, although initially the same, the number of movements during shock for the two groups diverged quickly over the first four shocks.

Intershock movements. The total number of movements for all intershock intervals during each half-session were averaged for each shock-treated rat for each of the two treatment sessions. Mean movements decreased over sessions and over halves within sessions for both groups. The mean numbers of intershock movements for the first half of Session 1 were 16.2 and 12.0 for Groups PS and ConS, respectively, and were 8.8 and 4.8 by the last half of Session 2. The only significant effects of an overall groups by sessions by session halves analysis were those attributable to sessions and session halves $(\mathrm{ps}<.01)$.

\section{Testing}

Response latencies. Figure 2 shows the mean shuttle latencies for each group, measured from the onset of the CS and averaged over the 12 trials on each of the 5 test days. The performance of Group ConS was considerably more impaired than that of the remaining groups. The overall mean latency for Group ConS was $19.8 \mathrm{sec}$; for Group PS, it was $9.6 \mathrm{sec}$. The comparable values for the restrained and unrestrained control groups were 9.4 and $11.8 \mathrm{sec}$, respectively.

A groups by days by trials analysis yielded significant effects for groups $[\mathrm{F}(3,36)=4.4, \mathrm{p}<.01]$, trials $[F(11,396)=2.11, p<.02]$, and days $[F(4,144)=6.68$, $\mathrm{p}<.002]$. Only the Groups by Trials interaction achieved significance $[F(33,396)=1.9, p<.01]$. In general, the response latencies for Group PS and the two control groups were relatively short on the initial trials of each day and either remained unchanged or decreased over the remaining test trials. In contrast, the generally much longer initial-trial latencies for Group ConS increased trials within a day. Averaged over days, mean latencies for Trials 1 and 12 were 10.9 and $10.7 \mathrm{sec}$ for Group PS, but were 14.9 and $21.9 \mathrm{sec}$ for Group ConS.

Paired comparisons were performed for each trial, collapsed over test days. None of the comparisons that involved the control groups and Group PS produced sig-

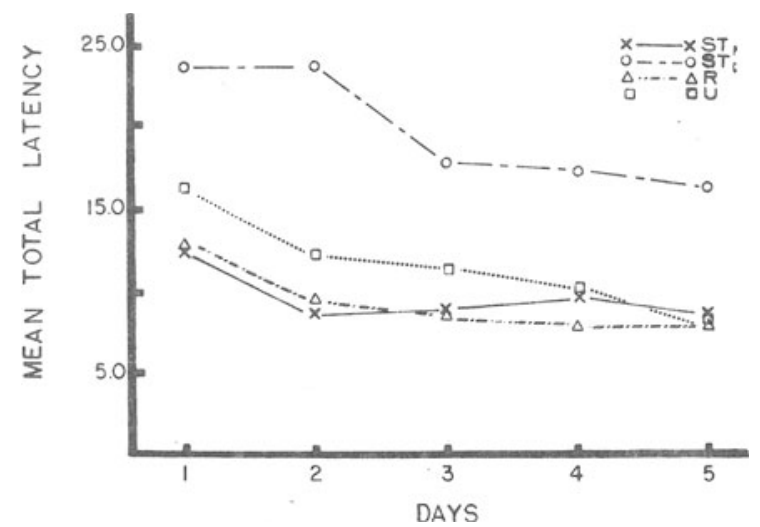

Figure 2. Mean daily shuttle response latencies from CS onset for groups that received either inescapable pulsating $\left(\mathrm{ST}_{\mathrm{p}}\right)$ or inescapable continuous $\left(\mathrm{ST}_{\mathrm{c}}\right)$ treatment shocks and for nonshocked restrained $(R)$ and unrestrained $(U)$ controls. nificant $t$ values (all ts $<1$ ). However, significant effects were obtained for paired comparisons between Group ConS and each of the other three groups for Trials 7-12.

Escape failures. Failures to escape were defined as response latencies in excess of $25 \mathrm{sec}$ from CS onset. A groups by days analysis produced significant effects for groups $[F(3,36)=3.95, p<.025]$ and days $(p<.01)$. Group ConS failed to escape more often than any other group (mean $=3.5$ failures overall). A comparison between Groups PS and ConS indicated a significant difference $[F(18)=2.5, p<.025]$. Comparisons of each shocktreated group with each control group (means $=1.0$, restrained; 1.6 , unrestrained) were significant for Group ConS $(p s<.025)$ but not for Group PS $($ mean $=1.0)$.

Number of avoidances. Rats in Group PS made more avoidances per day $($ mean $=3.0)$ than did the two control groups (mean $=2.2$ for the combined groups). Group ConS, however, made the fewest avoidances per day (mean $=1.5)$. A groups by days analysis yielded significant effects for groups $[\mathrm{F}(3,36)=3.02, \mathrm{p}<.05]$ and days $(\mathrm{p}<.01)$, the latter effect resulting from the fact that more avoidances were made by all groups in later test sessions. Individual paired comparisons showed that the groups effect resulted primarily from a significant difference in the performance of the two shock-treated groups $[F(1,18)=5.8, p<.03]$. The remaining comparisons did not achieve statistical significance.

\section{DISCUSSION}

The results clearly indicate that temporal form of inescapable shock is an important determinant of the magnitude of shuttle interference produced by such stimulation. A series of inescapable pulsating shocks resulted in no apparent debilitation of subsequent shuttle learning, in terms of the conventional indices of response latency, failures to escape, and avoidances; a similar series of inescapable continuous shocks produced marked impairment. Moreover, temporal form influenced the kind of behavior that occurred during the inescapable shock itself. The pulsating shock was accompanied by consistently high levels of movement, while the continuous stimulus, over the course of treatment, promoted relative immobility during shock.

One implication of the findings is that the effects of temporal form may account for our previous unpublished failures to find interference effects in the rat. In our earlier studies, we unwittingly selected a shock whose temporal form, in light of present results, is not conducive to the development of shuttle impairment. The inescapable shock in the early dog research, on the other hand, more closely resembled the continuous shock of the present study that was observed to produce marked impairment effects. Evidently, when procedures of the original dog research are employed with the rat, the shuttle interference phenomenon is critically dependent upon a feature of the shock stimulus that generally has gone unnoticed.

The second conclusion from the present findings is that the impairment effects were not dependent solely upon inescapability of treatment shock. Both pulsating and continuous shocks were programmed (by the experimenter) to be inescapable, yet only one produced interference. This finding would seem to be at odds with any view of the shuttle interference phenomenon that ascribes exclusive causal efficacy to the "uncontrollability" of treatment shock (e.g., Maier \& Seligman, 1976; Maier, Seligman, \& Solomon, 1969; Seligman, Maier, \& Solomon, 1971).

If temporal form rather than inescapability of treatment shock was the important determinant of interference in the present case, an unanswered question concerns the mechanism(s) whereby this variable was effective. One possibility is that a given duration of pulsating shock, because of its intermittent nature, involves more onsets and offsets, as well as a lower total amount of shock, than a comparable period of continuous shock. Therefore, the 
differential impairment produced by the latter condition could be the result of a greater total amount of shock. Although this possibility cannot be dismissed lightly, some of our unpublished data do not support this view.

Another view of the effects of temporal form is that duration of the individual shock-on periods during treatment may be important. Glazer and Weiss (1976) reported little or no interference in the rat unless the duration of each shock exposure during treatment was at least 5 sec. As an instance of this shock duration effect, one could contrast the duration of the shock-on periods for our pulsating-shock group $(.05 \mathrm{sec})$ with those of the continuous-shock group $(5 \mathrm{sec})$. However, for Glazer and Weiss (1976), shock-on time was important only as it related to the organism's tendency to develop distinctive behavior patterns during shock. They noted that longer duration inescapable shocks were more likely to promote immobility reactions than those of shorter duration. Thus, at least certain instances of interference effects were the result of the kind of behavior that developed during treatment shock coupled with the effect of that behavior on shuttle performance should it occur in the test situation. With respect to the present study, this view implies that the behavior promoted by the pulsating and continuous shocks during their successive 5-sec tenures may be the most important indicator of whether or not interference will follow. Indeed this seems to have been the case, in view of the general group correlations between activity during treatment shock and impairment during testing. Unfortunately, the negative relation between movement during treatment shock and degree of subsequent interference is not convincing evidence that the former determines the latter. In fact, physical differences between the pulsating and continuous shocks are still confounded with the different behaviors promoted. Nevertheless, this finding is consistent with the recent suggestions of Glazer and Weiss (1976), as well as with earlier competingresponse interpretations of the shuttle-interference phenomenon (e.g., Bracewell \& Black, 1974).

The implications of the present findings prompted a collaborative investigation (Lawry, Lupo, Overmier, Kochevar, Hollis, \& Anderson, 1978) comparing the effects of temporal form and shock type (ac vs. dc) in both dog and rat. For the dc conditions, a greater degree of standard shuttle behavior impairment was found in dog and rat following exposure to inescapable continuous shock than after comparable experience with inescapable pulsating shock. Thus, past failures to obtain interference effects in the rat using procedures comparable to those employed in the original dog research may be attributable more to unnoticed situational variables, such as the topography of shock, than to species differences, as some have suggested (Anisman \& Waller, 1973; Maier et al., 1973).

However, Lawry et al. (1978, Experiment 1) also observed an interaction of temporal form and shock type (ac vs. dc) with the dog. Both pulsating and continuous ac shock produced interference in this species. Unfortunately, shock source characteristics were confounded with the shock type variable in this study. Whereas the dc shock was generated with a standard constantcurrent source, the ac shock was produced by a constant-voltage device. With this latter source, variations in subject resistance have been shown to have dramatic effects on current flow through the organism despite a constant nominal voltage setting (Campbell \& Teghtsoonian, 1958). Thus, a progressive decrease in subject resistance throughout the shock treatment period would have been accompanied by a shock of increasing intensity for dogs exposed to an ac but not a dc shock type. In the comparable study with rats, however, Lawry et al. (1978, Experiment 2) employed a constant-current source to generate both shock types. In view of these circumstances, more parametric work is needed to determine what, if anything, the possible change in intensity of the ac shock contributed to the interaction of shock type and temporal form variables reported for dogs.

\section{REFERENCES}

Anisman, H., \& Waller, T. G. Facilitative and disruptive effect of prior exposure to shock on subsequent avoidance performance. Journal of Comparative and Physiological Psychology, 1972, 78, 113-122.

Anisman, H., \& Waller, T. G. Effects of inescapable shock on subsequent avoidance performance: Role of response repertoire changes. Behavioral Biology, 1973, 9, 331-355.

BRACEWELL, R. J., \& BLACK, A. H. The effects of restraint and noncontingent preshock on subsequent escape learning in the rat. Learning and Motivation, 1974, 5, 53-69.

Campbell, B. A., \& Teghtsoonian, R. Electrical and behavioral effects of different types of shock stimuli on the rat. Journal of Comparative and Physiological Psychology, 1958, 51, 185-192.

D' Amato, M. R., \& Fazzaro, J. Discriminated lever-press avoidance learning as a function of type and intensity of shock. Journal of Comparative and Physiological Psychology, 1966, 61, 313-315.

GLAZER, H. I., \& WEISS, J. M. Long-term and transitory interference effects. Journal of Experimental Psychology: Animal Behavior Processes, 1976, 2, 191-201.

Lawry, J. A., Lupo, V., Overmier, J. J., Kochevar, J., Hollis, K. L., \& ANDERSON, D. C. Interference with avoidance behavior - as a function of qualitative properties of inescapable shocks. Animal Learning \& Behavior, 1978, 6, 147-154.

LOONEY, T. A., \& CoHEN, P. S. Retardation of jump-up escape responding in rats pretreated with different frequencies of noncontingent electric shock. Journal of Comparative and Physiological Psychology, 1972, 78, 317-322.

LYKKEN, D. T., \& Rose, R. A rat-holder with electrodes for GSR measurement. American Journal of Psychology, 1959, 72, 621-622.

Maier, S. F., Albin, R. W., \& Testa, T. Failure to learn to escape shock in rats previously exposed to inescapable shock depends on nature of escape response. Journal of Comparative and Physiological Psychology, 1973, 85, 581-592.

Maier, S. F., \& Seligman, M. E. P. Learned helplessness: Theory and evidence. Journal of Experimental Psychology: General, 1976, 105, 3-46.

Maier, S. F., Seligman, M. E. P., \& Solomon, R. L. Pavlovian fear conditioning and learned helplessness: Effects on escape and avoidance behavior of (a) the CS-US contingency and (b) the independence of the US and voluntary responding. In B. A. Campbell \& R. M. Church (Eds.), Punishment and aversive behavior. New York: Appleton-Century-Crofts, 1969.

MAIER, S. F., \& TESTA, T. J. Failure to learn to escape by rats previously exposed to inescapable shock is partly produced by associative interference. Journal of Comparative and Physiological Psychology, 1975, 88, 554-564.

Mullin, A. D., \& Mogenson, G. J. Effects of fear conditioning on avoidance learning. Psychological Reports, 1963, 13, 707-710.

Overmier, J: B., \& Seligman, M. E. P. Effects of inescapable shock upon subsequent escape and avoidance responding. Journal of Comparative and Physiological Psychology, 1967, 63, 28-33.

Seligman, M. E. P., \& Maier, S. F. Failure to escape traumatic shock. Journal of Experimental Psychology, 1967, 74, 1-9.

Seligman, M. E. P., Maier, S. F., \& Solomon, R. L. Unpredictable and uncontrollable aversive events. In F. R. Brush (Ed.), Aversive conditioning and learning. New York: Academic Press, 1971. Pp. 347-400.

Seligman, M. E. P., Rosellini, R. A., Kozak, M. Learned helplessness in the rat: Reversibility, time course, and immunization. Journal of Comparative and Physiological Psychology, 1975, 88, 542-547.

Shurman, A. J., \& Katzev, R. D. Escape/avoidance responding in rats depends on strain and number of inescapable preshocks. Journal of Comparative and Physiological Psychology, 1975, 88, 548-553.

Weiss, J. M., Krieckhaus, E. E., \& Conte, R. Effects of fear conditioning on subsequent avoidance behavior and movement. Journal of Comparative and Physiological Psychology, 1968, 65, 413-421.

(Received for publication October 31, 1978.) 